\title{
On the crystallisation pressure of gypsum
}

\section{Journal Article}

\section{Author(s):}

Serafeimidis, Konstantinos; Anagnostou, Georg

Publication date:

2014-12

Permanent link:

https://doi.org/10.3929/ethz-b-000087851

Rights / license:

In Copyright - Non-Commercial Use Permitted

Originally published in:

Environmental Earth Sciences 72(12), https://doi.org/10.1007/s12665-014-3366-7 


\title{
On the crystallisation pressure of gypsum
}

\author{
K. Serafeimidis · G. Anagnostou
}

Received: 19 February 2014/ Accepted: 16 May 2014/Published online: 4 June 2014

(C) Springer-Verlag Berlin Heidelberg 2014

\begin{abstract}
We estimate the crystallisation pressure of gypsum quantitatively, with reference to the geological context of the Gypsum Keuper formation. The formation contains sulphatic claystones which have the property of swelling in the presence of water and have caused substantial structural damage to the linings of several tunnels in Switzerland and Germany. The swelling of these rocks is attributed to the transformation of anhydrite into gypsum, which occurs via the dissolution of anhydrite in pore water and the precipitation of gypsum from the solution. This simultaneous dissolution-precipitation process happens because the solubility of gypsum is lower than that of anhydrite under the conditions prevailing after tunnelling, and it does not cease until all of the anhydrite has been transformed. The elementary mechanism behind the development of the macroscopically observed swelling pressure is the growth of gypsum crystals inside the rock matrix: If a crystal is in contact with a supersaturated solution, but its growth is prevented by the surrounding matrix, it then exerts a so-called crystallisation pressure upon the pore walls. In the present paper, the crystallisation pressure is calculated by means of a thermodynamic model that takes coherent account of all relevant parameters, including the chemical composition of the pore water and pore size. Variations in these parameters lead to a very wide range of crystallisation pressures (from zero to several tens of megapascals). By using the results of mercury intrusion porosimetry and chemical analyses of samples from three Swiss tunnels, however, we show that the range of predicted values can be reduced significantly with the help of standard, project-specific investigations.
\end{abstract}

K. Serafeimidis · G. Anagnostou ( $₫)$

ETH Zurich, Zurich, Switzerland

e-mail: georg.anagnostou@igt.baug.ethz.ch
Keywords Gypsum · Anhydrite $\cdot$ Crystallisation pressure · Gypsum Keuper

\section{List of symbols}

c Concentration

$c_{\mathrm{i}} \quad$ Concentration of ion $i$

$c_{\mathrm{Ca}^{2+}} \quad$ Concentration of calcium ions

$c_{\text {eq,A }}$ Anhydrite equilibrium concentration

$c_{\mathrm{eq}, \mathrm{G}}^{0}$ Gypsum equilibrium concentration at standard state

$c_{\mathrm{SO}_{4}^{2-}} \quad$ Concentration of sulphate ions

$K \quad$ Ion activity product

$K_{\text {eq,A }}^{0} \quad$ Equilibrium solubility product of anhydrite at standard state

$K_{\text {eq,G }}^{0} \quad$ Equilibrium solubility product of gypsum at standard state

$K_{\text {sp }} \quad$ Solubility product in Flückiger's (1994) model

$K_{\mathrm{sp}}^{0} \quad$ Solubility product at standard state in Flückiger's (1994) model

$n \quad$ Pore percentage

$p_{\mathrm{G}} \quad$ Crystallisation pressure

$p_{\mathrm{G} 1} \quad$ Crystallisation pressure at state 1

$p_{\mathrm{G} 2} \quad$ Crystallisation pressure at state 2

$R \quad$ Universal gas constant

$r_{\mathrm{G}} \quad$ Radius of gypsum particles

$r_{\mathrm{p}} \quad$ Pore radius

$S_{\mathrm{A}}^{0} \quad$ Molar entropy of anhydrite at standard state

$S_{\mathrm{G}}^{0} \quad$ Molar entropy of gypsum at standard state

$S_{\mathrm{W}}^{0} \quad$ Molar entropy of water at standard state

$\mathrm{T}$ Temperature

$T_{0} \quad$ Temperature at standard state

$V_{\mathrm{A}}^{0} \quad$ Molar volume of anhydrite at standard state

$V_{\mathrm{G}}^{0} \quad$ Molar volume of gypsum at standard state 


\section{Greek symbols}

$\alpha_{\mathrm{W}} \quad$ Water activity

$\alpha_{i} \quad$ Activity of ion $i$

$\gamma_{\mathrm{Ca}^{2+}} \quad$ Activity coefficient of calcium ions

$\gamma_{\mathrm{G}} \quad$ Surface free energy of the gypsum-water interface

$\gamma_{i} \quad$ Activity coefficient of ion $i$

$\gamma_{\mathrm{SO}_{4}^{2-}} \quad$ Activity coefficient of sulphate ions

$\Delta G_{r} \quad$ Free energy of the transformation of anhydrite to gypsum in Flückiger's (1994) model

$\Delta_{r, \mathrm{~A}} G^{0} \quad$ Standard Gibbs energy of anhydrite dissolution

$\Delta_{r, \mathrm{~A}} S^{0} \quad$ Standard entropy of anhydrite dissolution

$\Delta_{r, \mathrm{~A}} V^{0} \quad$ Standard volume of anhydrite dissolution

$\Delta_{r, \mathrm{GA}} G^{0}$ Standard Gibbs energy of the transformation of anhydrite to gypsum

$\Delta_{r, \mathrm{GA}} S^{0}$ Standard entropy of the transformation of anhydrite to gypsum

$\Delta_{r, \mathrm{GA}} V^{0}$ Standard volume of the transformation of anhydrite to gypsum

$\Delta_{r, \mathrm{G}} G^{0} \quad$ Standard Gibbs energy of gypsum dissolution

$\Delta_{r, \mathrm{G}} S^{0} \quad$ Standard entropy of gypsum dissolution

$\Delta_{\mathrm{r}, \mathrm{G}} V^{0} \quad$ Standard volume of gypsum dissolution

\section{Introduction}

With water uptake, swelling sulphatic rocks exert a pressure upon a tunnel lining which may endanger its structural safety (Amstad and Kovári 2001). The swelling is attributed mainly to the chemical transformation of anhydrite into gypsum, a process that takes place via the solution phase. The microscopic mechanism behind the development of the swelling pressure is the growth of gypsum crystals inside the rock matrix: If a crystal is in contact with a supersaturated solution, then it will grow or, if its growth is entirely prevented by the surrounding matrix, then it will exert a so-called crystallisation pressure upon the pore walls (Correns and Steinborn 1939).

There are few works in the literature dealing specifically with the crystallisation pressure of gypsum in sulphatic claystones. Winkler and Singer (1972) and Winkler (1973) estimated crystallisation pressure on the basis of Correns and Steinborn's theory (1939), according to which the crystallisation pressure $p_{\mathrm{G}}$ of a crystal in equilibrium with a solution of concentration $c$ reads as follows:

$p_{\mathrm{G}}=\frac{R T}{V_{\mathrm{G}}^{0}} \ln \left(\frac{c}{c_{\mathrm{eq}, \mathrm{G}}^{0}}\right)$,

where $c_{e q, G}^{0}$ is the equilibrium concentration of gypsum at standard conditions (i.e. dilute solutions under atmospheric pressure and at $T=25^{\circ} \mathrm{C}$ ); $c$ is the ion concentration (or, equivalently, the equilibrium concentration when the gypsum is subjected to the pressure $\left.p_{\mathrm{G}}\right) ; R$ is the universal gas constant; $T$ is the temperature; and $V_{G}^{0}$ is the molar volume of gypsum. According to Eq. (1), supersaturation $c / c_{\mathrm{eq}, \mathrm{G}}^{0}$ is the driving force for the development of crystallisation pressure. (The higher the concentration, the higher will be the crystallisation pressure for a given equilibrium concentration). Winkler and Singer (1972) and Winkler (1973) calculated the crystallisation pressure of gypsum as a function of supersaturation for different temperatures $\left(0,25\right.$ and $\left.50{ }^{\circ} \mathrm{C}\right)$. However, they erroneously considered a molar volume of gypsum of $V_{\mathrm{G}}^{0}=54.8 \mathrm{~cm}^{3} / \mathrm{mol}$ instead of the correct value $\left(74.3 \mathrm{~cm}^{3} / \mathrm{mol}\right)$. In addition, Eq. (1) does not take the activities of the reacting substances into account. The concentrations in Eq. (1) should be replaced by the solubility products ( $c f$. . Ping and Beaudoin 1992a; Flatt et al. 2007):

$p_{\mathrm{G}}=\frac{R T}{V_{\mathrm{G}}^{0}} \ln \frac{K}{K_{\mathrm{eq}, \mathrm{G}}^{0}}$,

where $K$ denotes the ion activity product of the solution and $K_{\text {eq,G }}^{0}$ the equilibrium solubility product of gypsum at standard conditions. Figure 1 shows the crystallisation pressure as a function of the supersaturation for $T=25^{\circ} \mathrm{C}$ and atmospheric pressure: Curve 1 is according to Winkler (1973), i.e. it does not take account of the activities and assumes a value for the molar volume, which is lower than the actual one; Curve 2 has the correct value for the molar volume but neglects the effect of activity; and Curve 3 is based upon Eq. (2) with a correct value for the molar volume. The incorrect assumption about molar volume (Curve 1) leads to a considerable overestimation of the crystallisation pressure (compared to Curve 2), but when combined with the simplifying assumption mentioned above (activity equal to unity) coincidentally leads to results which are close to the correct values (Curve 3).

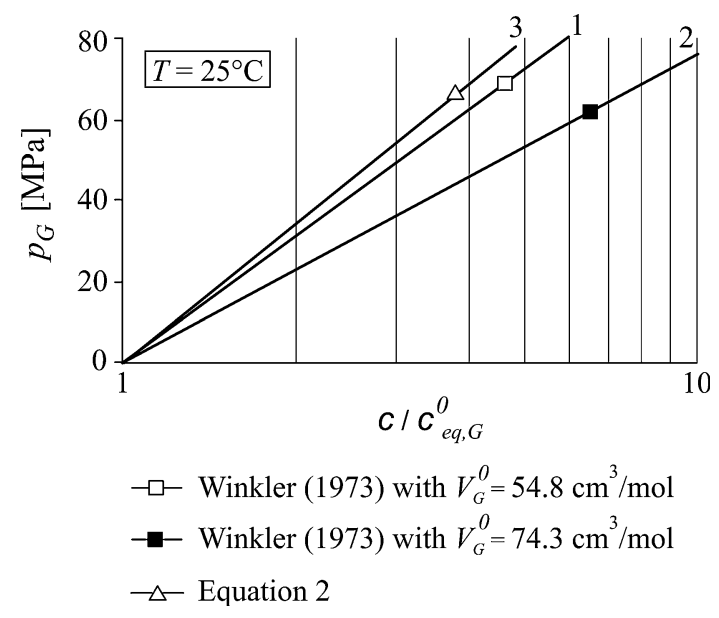

Fig. 1 Crystallisation pressure $p_{\mathrm{G}}$ of gypsum as a function of supersaturation $c / c_{e q, G}^{0}$ 
The results of Winkler (1973) were later adopted by Wichter (1989). Assuming that supersaturation rarely exceeds 2 in Gypsum Keuper, he concluded that the crystallisation pressure amounts to about $30 \mathrm{MPa}$ at $T=25^{\circ} \mathrm{C}$. Nevertheless, he did not substantiate his assumption concerning supersaturation empirically or theoretically.

Another theoretical estimate can be found in Flückiger (1994) and Flückiger et al. (1994), who determined a value of $3.7 \mathrm{MPa}$ for the crystallisation pressure of gypsum at room temperature $\left(T=20^{\circ} \mathrm{C}\right)$ by means of thermodynamic calculations. This value was later used by Steiner et al. (2010), who investigated the role of the brittle fracture process on the swelling of anhydritic claystones. The value of 3.7 $\mathrm{MPa}$ is lower than all previous thermodynamic estimates and also lower than the swelling pressures frequently measured in swelling pressure tests under volume constraint (see Pimentel 2007). The value is based, however, upon erroneous thermodynamic considerations and questionable assumptions. More specifically, Flückiger et al. (1994) used the relationship

$p_{\mathrm{G}}=\frac{R T}{V_{\mathrm{G}}^{0}} \ln \frac{K_{\mathrm{sp}}}{K_{\mathrm{sp}}^{0}}$

which resembles Eq. (2), but, rather than considering the actual ionic concentration, they determined the solubility products that appear in the right-hand side of Eq. (3) as follows:

$K_{\mathrm{sp}}=\exp \left(-\frac{\Delta G_{r}(T)}{R T}\right)$,

$K_{\mathrm{sp}}^{0}=\exp \left(-\frac{\Delta G_{r}\left(T_{0}\right)}{R T_{0}}\right)$,

where $\Delta G_{r}$ denotes the free energy of the transformation of anhydrite into gypsum at temperature $T$, calculated by using the following empirical relationship of Kelley et al. 1941 (see also Gmelin 1961):

$$
\begin{aligned}
\Delta G_{r}[\mathrm{~J} / \mathrm{mol}]= & 10439+273 T \log _{10} T-0.09 T^{2} \\
& -686 T(T \text { in }[\mathrm{K}]) .
\end{aligned}
$$

Flückiger et al. (1994) did not explicitly mention the use of Eqs. (4) and (5), but they must have use these equations, as Eqs. (4) and (5) lead exactly to their numerical values for the solubility product $K_{\mathrm{sp}}$ (1.57 and 1.40 at $T=20$ and $25^{\circ} \mathrm{C}$, respectively). As shown in "Appendix", the pressure calculated by Flückiger et al. (1994) is actually the increase in the crystallisation pressure that would occur, if the temperature drops from $T_{0}=25^{\circ}$ to $T=20{ }^{\circ} \mathrm{C}$ with the solution being continuously saturated with respect to anhydrite. The value of 3.7 $\mathrm{MPa}$ thus lacks practical relevance. The actual crystallisation pressure at $20^{\circ} \mathrm{C}$ is by one order of magnitude higher (20-54 MPa, see Fig. 4a in "Closed system" section).

Furthermore, it should be noted that existing theoretical studies into the crystallisation pressure of gypsum do not consider all of the relevant parameters. Besides the temperature $T$ and the concentration $c$ of the calcium and sulphate ions, the presence of foreign ions in the solution as well as clay minerals affects the thermodynamic equilibrium by reducing the activities of the reactants (Serafeimidis and Anagnostou 2014) and therefore influences the crystallisation pressure. Furthermore, in a fineporous rock, the effect of the liquid-solid surface energy becomes relevant, with the consequence that crystallisation pressure also depends on the shape and size of the pores (Scherer 1999; Flatt 2002; Steiger 2005). The present paper aims to close knowledge gaps as to the crystallisation pressure of gypsum by quantifying these effects and by discussing the factors affecting supersaturation in the context of the sulphatic claystones of the Gypsum Keuper formation.

The paper is organised as follows: After some thermodynamic preliminaries ("Thermodynamic preliminaries" section), we show the extent to which pore size (assuming spherical pores), temperature and the presence of clay minerals or foreign ions may influence the relationship between crystallisation pressure and ion concentration $c$ ("Relationship between crystallisation pressure and concentration" section). In the parametric analyses of "Relationship between crystallisation pressure and concentration" section, the concentration $c$ of the sulphate and calcium ions, which, as mentioned above, represents the driving force of the crystallisation process, is taken as an independent, given parameter. The concentration of the sulphate and calcium ions in the pore water is the result of anhydrite dissolution and gypsum precipitation and, in an open system, also of transport processes (advection and diffusion). "On the ion concentration" and "Closing remarks" sections deal with the value of this parameter in open and closed systems, respectively. All computations will be carried out under the simplifying assumption of atmospheric pore water pressure, because the effect of the pore water pressure is small for the relevant range of values in shallow tunnels (up to $2 \mathrm{MPa}$ only).

\section{Thermodynamic preliminaries}

The computations of the next sections are based upon the condition of thermodynamic equilibrium between gypsum and pore solution, which can be expressed as follows (Serafeimidis and Anagnostou 2014): 


$$
\begin{aligned}
R T & \ln \left(\gamma_{\mathrm{Ca}^{2+}} \gamma_{\mathrm{SO}_{4}^{2-}} \frac{c_{\mathrm{Ca}^{2+}}}{c_{0}} \frac{c_{\mathrm{SO}_{4}^{2-}}}{c_{0}} a_{\mathrm{W}}^{2}\right) \\
= & -\Delta_{r, \mathrm{G}} G^{0}+\left(p_{\mathrm{G}}+\frac{2 \gamma_{\mathrm{G}}}{r_{\mathrm{G}}}\right) V_{\mathrm{G}}^{0}+\left(T-T_{0}\right) \Delta_{r, \mathrm{G}} S^{0} .
\end{aligned}
$$

This equation links the calcium and sulphate concentrations $c_{\mathrm{Ca}^{2+}}$ and $c_{\mathrm{SO}_{4}^{2-}}$ to the gypsum pressure $p_{\mathrm{G}}$ under the simplifying assumption of atmospheric pore water pressure. The symbols $c_{0}$ and $T_{0}$ denote the standard concentration $(1 \mathrm{~mol} / \mathrm{l})$ and the standard temperature $(273 \mathrm{~K}$ or $25{ }^{\circ} \mathrm{C}$ ), respectively. The radius $r_{\mathrm{G}}$ of the gypsum particles is taken equal to the pore radius $r_{\mathrm{P}}$, because the size of the intergranular space limits the maximum size of the gypsum crystals. The surface energy of gypsum $\gamma_{\mathrm{G}}$ can be taken equal to about $80 \mathrm{mN} / \mathrm{m}$ (Serafeimidis and Anagnostou 2014). $\alpha_{\mathrm{W}}$ is the water activity, while $\gamma_{\mathrm{Ca}^{2+}}$ and $\gamma_{\mathrm{SO}_{4}^{2-}}$ denote the activity coefficients of the dissolved calcium and sulphate ions, respectively. The activity coefficients depend on all ionic concentrations and can be calculated by means of several theoretical models (cf. Merkel and Planer-Friedrich 2008). Here, the equations of Davies (1962) will be used, because the ionic strengths are low in the sulphatic claystones of the Gypsum Keuper formation (see Serafeimidis and Anagnostou 2014, for details). The other symbols appearing in Eq. (7) are thermodynamic constants (see Notation and Table 1). Solving Eq. (7) with respect to the gypsum pressure $p_{\mathrm{G}}$ leads to the following expression for crystallisation pressure:

$$
\begin{aligned}
p_{\mathrm{G}}= & \frac{R T \ln \left(\gamma_{\mathrm{Ca}^{2+}} \gamma_{\mathrm{SO}_{4}^{2-}} \frac{c_{\mathrm{Ca}^{2+}}}{c_{0}} \frac{{ }_{\mathrm{SO}_{4}^{2-}}}{c_{0}}\right)+\Delta_{r, \mathrm{G}} G^{0}-\left(T-T_{0}\right) \Delta_{r, \mathrm{G}} S^{0}}{V_{\mathrm{G}}^{0}} \\
& +\frac{2 R T \ln a_{\mathrm{W}}}{V_{\mathrm{G}}^{0}}-\frac{2 \gamma_{\mathrm{G}}}{r_{\mathrm{P}}} .
\end{aligned}
$$

In the specific case of a closed system containing anhydrite, water and gypsum, the supersaturation with

\begin{tabular}{|c|c|c|c|c|c|}
\hline \multicolumn{3}{|c|}{ Molar entropies } & \multicolumn{3}{|c|}{ Molar volumes } \\
\hline$S_{A}^{0}$ & 106.70 & $\mathrm{~J} / \mathrm{mol} / \mathrm{K}$ & $V_{A}^{0}$ & 45.94 & $\mathrm{~cm}^{3} / \mathrm{mol}$ \\
\hline$S_{G}^{0}$ & 194.10 & $\mathrm{~J} / \mathrm{mol} / \mathrm{K}$ & $V_{G}^{0}$ & 74.30 & $\mathrm{~cm}^{3} / \mathrm{mol}$ \\
\hline$S_{W}^{0}$ & 69.91 & $\mathrm{~J} / \mathrm{mol} / \mathrm{K}$ & $V_{W}^{0}$ & 18.00 & $\mathrm{~cm}^{3} / \mathrm{mol}$ \\
\hline \multicolumn{3}{|c|}{ Anhydrite dissolution } & \multicolumn{3}{|c|}{ Gypsum dissolution } \\
\hline$\Delta_{r, A} G^{0}$ & 23,680 & $\mathrm{~J} / \mathrm{mol}$ & $\Delta_{r, \mathrm{G}} G^{0}$ & 24,930 & $\mathrm{~J} / \mathrm{mol}$ \\
\hline$\Delta_{r, \mathrm{~A}} S^{0}$ & -139.7 & $\mathrm{~J} / \mathrm{K} / \mathrm{mol}$ & $\Delta_{r, \mathrm{G}} S^{0}$ & -87.28 & $\mathrm{~J} / \mathrm{K} / \mathrm{mol}$ \\
\hline$\Delta_{r, \mathrm{~A}} V^{0}$ & -50.36 & $\mathrm{~cm}^{3} / \mathrm{mol}$ & $\Delta_{r, \mathrm{G}} V^{0}$ & -42.72 & $\mathrm{~cm}^{3} / \mathrm{mol}$ \\
\hline \multicolumn{3}{|c|}{ Anhydrite hydration } & \multicolumn{3}{|c|}{ Other constants } \\
\hline$\Delta_{r, \mathrm{GA}} G^{0}$ & $-1,250$ & $\mathrm{~J} / \mathrm{mol}$ & $\gamma_{\mathrm{G}}$ & 80 & $\mathrm{mN} / \mathrm{m}$ \\
\hline$\Delta_{r, \mathrm{GA}} S^{0}$ & -52.42 & $\mathrm{~J} / \mathrm{K} / \mathrm{mol}$ & $R$ & 8.314 & $\mathrm{~J} / \mathrm{K} / \mathrm{mol}$ \\
\hline$\Delta_{r, \mathrm{GA}} V^{0}$ & -7.64 & $\mathrm{~cm}^{3} / \mathrm{mol}$ & $T_{0}$ & 273.15 & $\mathrm{~K}$ \\
\hline
\end{tabular}

Table 1 Values of the thermodynamic constants (after Anderson 1996, with the exception of $\gamma_{\mathrm{G}}$, which is after Serafeimidis and Anagnostou 2014) respect of gypsum is due to the fact that the solubility of anhydrite is higher than that of gypsum. The concentrations in this case are equal to the solubility of anhydrite (see "Closed system" section for more details) and are obtained by considering the condition of thermodynamic equilibrium between anhydrite and pore solution, which can be expressed, analogously to Eq. (7), as follows:

$$
\begin{aligned}
R T & \ln \left(\gamma_{\mathrm{Ca}^{2+}} \gamma_{\mathrm{SO}_{4}^{2-}} \frac{c_{\mathrm{Ca}^{2+}}}{c_{0}} \frac{c_{\mathrm{SO}_{4}^{2-}}}{c_{0}}\right) \\
= & -\Delta_{r, \mathrm{~A}} G^{0}+p_{\mathrm{A}} V_{\mathrm{A}}^{0}+\left(T-T_{0}\right) \Delta_{r, \mathrm{~A}} S^{0},
\end{aligned}
$$

where $p_{\mathrm{A}}$ denotes the anhydrite pressure. The term expressing the effect of the liquid-solid interfacial energy was omitted from Eq. (9), because the surface effects are negligible for radii $>1 \mu \mathrm{m}$ (Serafeimidis and Anagnostou 2014) and anhydrite appears in natural rocks either in the form of layers or of particles with sizes of few $\mu \mathrm{m}$ to few cm (Serafeimidis and Anagnostou 2012).

\section{Relationship between crystallisation pressure and concentration}

Figure 2 shows the relationship between crystallisation pressure and concentration $c$ (assuming equal calcium and sulphate concentrations, i.e. $c_{\mathrm{Ca}^{2+}}=c_{\mathrm{SO}_{4}^{2-}}=c$ ) for different values of the other parameters.

Taking the radius $r_{\mathrm{G}}$ of the gypsum particles equal to the pore radius $r_{\mathrm{P}}$ ("Thermodynamic preliminaries" section), Fig. 2a shows the effect of the solid-liquid interfacial energy, which is expressed by the term $2 \gamma_{\mathrm{G}} / r_{\mathrm{P}}$ in Eq. (8). It decreases with increasing pore size $r_{\mathrm{P}}$ and can be totally neglected for radii $>1 \mu \mathrm{m}$. For small radii $r_{\mathrm{P}}$, however, it is relevant: The surface of the crystal can be conceived as a stretched membrane, which exerts a pressure upon the crystal, thus taking over a part of the crystallisation pressure; the crystallisation pressure decreases, therefore, with decreasing radius $r_{P}$ (Scherer 1999; Steiger 2005). This can be seen also from Eq. (8), according to which the surface energy effect reduces the crystallisation pressure by $2 \gamma_{\mathrm{G}} / r_{\mathrm{P}}$. Consider, for example, a pore solution with a high sulphate content of $25 \mathrm{mmol} / \mathrm{l}(2400 \mathrm{mg} / \mathrm{l})$. The crystallisation pressure is in this case equal to about $24 \mathrm{MPa}$ in large pores but drops below few MPa in the small pores.

Figure $2 \mathrm{~b}$ concerns the effect of the water activity $a_{\mathrm{W}}$. As can be readily verified by inspecting Eq. (8), a water activity $a_{\mathrm{W}}<1$ reduces the crystallisation pressure by $\left|2 R T \ln a_{\mathrm{W}} / V_{G}^{0}\right|$. The water activity $a_{\mathrm{W}}$ expresses the ability of water to participate in chemical reactions (gypsum precipitation in the present case). Clay minerals or a high ionic concentration may reduce water activity considerably (For a discussion of the effect of clay minerals, see 
Fig. 2 Crystallisation pressure $p_{\mathrm{G}}$ of gypsum as a function of ion concentration $c$ : a effect of pore radius $r_{\mathrm{P}} ; \mathbf{b}$ effect of water activity $a_{\mathrm{W}}$; $\mathbf{c}$ effect of foreign ions; $\mathbf{d}$ effect of the temperature $T$
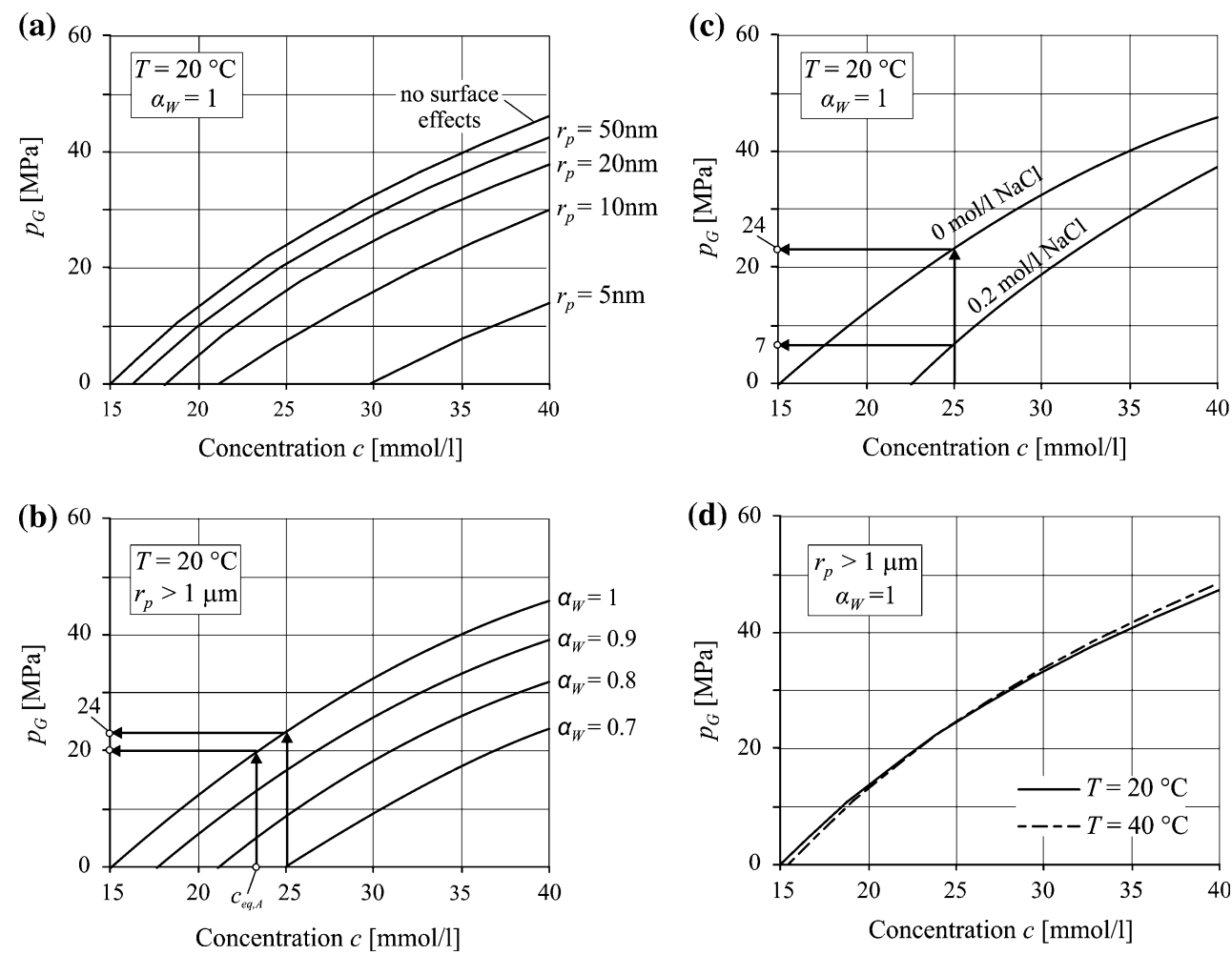

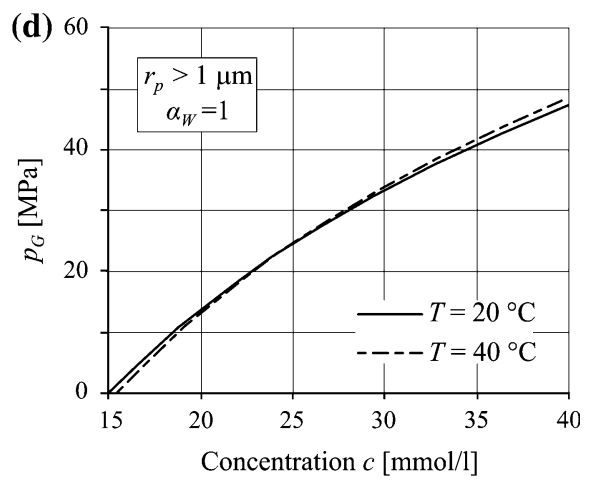

Serafeimidis and Anagnostou 2014). At a concentration of $25 \mathrm{mmol} / \mathrm{l}$ (i.e. a sulphate content of $2,400 \mathrm{mg} / \mathrm{l}$ ), the crystallisation pressure amounts to 0-24 MPa depending on the water activity (0.7-1.0).

Foreign ions (e.g. sodium or chloride) decrease the activities of all reactants (water, calcium and sulphate ions) that participate in the growth of gypsum and thus also its crystallisation pressure. This is taken into account in Eq. (8) via the water activity $\alpha_{\mathrm{W}}$ and the ion activity coefficients $\gamma_{\mathrm{Ca}^{2+}}$ and $\gamma_{\mathrm{SO}_{4}^{2-}}$. Figure 2c compares the crystallisation pressure in the case of a $\mathrm{NaCl}$ solution of $0.2 \mathrm{~mol} / 1 \mathrm{H}_{2} \mathrm{O}$ with the crystallisation pressure in the absence of foreign ions. For the sake of simplicity, the water activity, which is only slightly lower than 1 at this $\mathrm{NaCl}$ concentration (Washburn Washburn 1926-1933), was taken equal to 1 . Figure $2 \mathrm{c}$ shows that even in the case of a solution of high sulphate content $(25 \mathrm{mmol} / \mathrm{l})$, the presence of dissolved $\mathrm{NaCl}(0.2 \mathrm{~mol} / \mathrm{l})$ reduces the crystallisation pressure from about $24 \mathrm{MPa}$ to about $7 \mathrm{MPa}$ for given concentration $c$.

As the temperature affects several terms of Eq. (8), its effect cannot be seen immediately. Figure $2 d$ shows that it has a minor effect on the crystallisation pressure. It should be noted that this conclusion is true only for given concentration $c$, i.e. under the assumption that the concentration itself does not depend on the temperature. As we will see in "Closed system" section, however, in a closed system containing gypsum, anhydrite and water, the concentration $c$ is equal to the equilibrium concentration $c_{\mathrm{eq}, \mathrm{A}}$ of anhydrite, which is very sensitive to the temperature (Marsal 1952; Blount and Dickson 1973). In this particular case, the crystallisation pressure of the gypsum also depends on the temperature (see end of "Closed system" section).

In view of the paramount effect of the concentration $c$ (Fig. 2), the next section deals with the value of this parameter, first in a closed system containing anhydrite, water and gypsum, and afterwards in an open system.

\section{On the ion concentration}

\section{Closed system}

Let us first consider the concentration and the corresponding crystallisation pressure that would develop in a closed system consisting of anhydrite, water and gypsum. As in a closed system water and ions cannot flow in or out, anhydrite is the only supplier of ions and the latter are consumed only by the precipitation of gypsum. Assume, for the sake of simplicity, that the pore water is initially distilled. In this case, anhydrite dissolution would occur, increasing thus the concentration of ions in the pore water. The dissolution process would cease, when the concentration reaches the equilibrium concentration $c_{\mathrm{eq}, \mathrm{A}}$ of anhydrite. The latter can be determined by means of Eq. (9). Under atmospheric pressure $\left(p_{\mathrm{A}}=0\right)$ and $T=20^{\circ} \mathrm{C}$, it is 
equal to $23.4 \mathrm{mmol} / \mathrm{l}$. As this concentration is higher than the equilibrium concentration of gypsum under the same conditions ( $15 \mathrm{mmol} / \mathrm{l}$, determined from Eq. (8) with $p_{\mathrm{G}}=0$, neglecting the effects of water activity and surface energy), gypsum will develop a crystallisation pressure of about $20 \mathrm{MPa}$ (see, e.g. Fig. $2 \mathrm{~b}$ for $c=c_{\mathrm{eq}, \mathrm{A}}=23.4$ $\mathrm{mmol} / \mathrm{l}$ and $\alpha_{\mathrm{W}}=1$ ). The development of this pressure may cause a certain increase also in the pressure $p_{\mathrm{A}}$ acting on the anhydrite particles, because the growth of the gypsum is constrained by the surrounding medium. In the extreme case, where the constrained gypsum crystals are very closely spaced and located close to the anhydrite grains, the pressure developing upon the latter can be taken approximately equal to the crystallisation pressure of the gypsum. In general, the anhydrite pressure will be between atmospheric and gypsum pressure.

The increased anhydrite pressure will cause an increase in the equilibrium concentration of anhydrite to a value, which is higher than the equilibrium concentration under atmospheric pressure $(23.4 \mathrm{mmol} / \mathrm{l})$. In turn, this will further increase the crystallisation pressure of gypsum to more than the value of $20 \mathrm{MPa}$ estimated above, which will again further increase the equilibrium concentration of anhydrite. The process of a successive pressure-induced increase in the equilibrium concentration of the dissolving mineral is well known from petrography (see, e.g. Merino and Dewers 1998). It can be illustrated graphically by plotting in one and the same diagram the following two curves (Fig. 3): (1) the crystallisation pressure $p_{\mathrm{G}}$ of the gypsum as a function of the concentration $c$ (curve " $p_{\mathrm{G}}$ ", determined by Eq. (8) with $c_{\mathrm{Ca}^{2+}}=c_{\mathrm{SO}_{4}^{2-}}=c$ ) and (2) the relationship between the pressure $p_{\mathrm{A}}$ acting upon the anhydrite particles and the equilibrium concentration of anhydrite (curve " $p_{\mathrm{A}}$ ", determined by Eq. 9).

Points 1 and 2 in Fig. 3 show the equilibrium concentration of anhydrite under atmospheric pressure and the corresponding crystallisation pressure of gypsum,

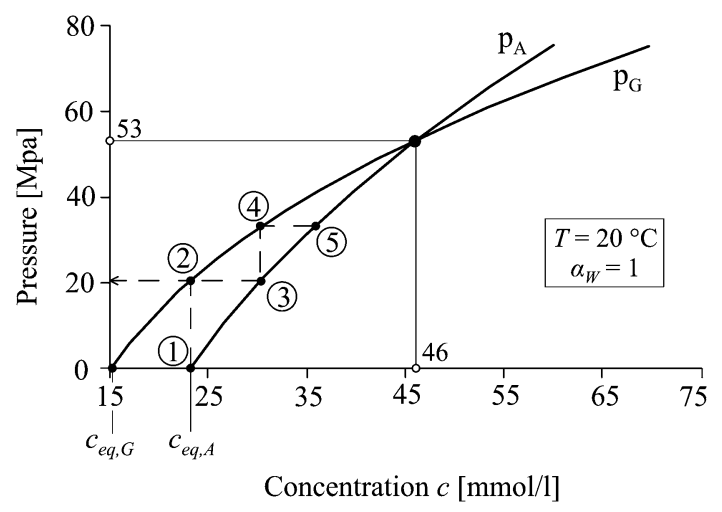

Fig. 3 Relationship between the crystallisation pressure of gypsum and the ion concentration as well as between the pressure and equilibrium concentration of anhydrite respectively. Point 3 shows the increased equilibrium concentration of anhydrite assuming that the crystallisation pressure of $20 \mathrm{MPa}$ also acts upon the anhydrite particles. At this higher concentration, the crystallisation pressure of gypsum would also be higher (about 30-35 MPa, point 4), which would in turn increase the equilibrium concentration of anhydrite (point 5) and so on. The system reaches equilibrium only at the intersection point of the two curves. At this point, the equilibrium concentration of anhydrite amounts to about $46 \mathrm{mmol} / \mathrm{l}$ (about twice the equilibrium concentration under atmospheric pressure) and the crystallisation pressure of gypsum to $53 \mathrm{MPa}$.The crystallisation pressure at equilibrium can be obtained by setting $p_{\mathrm{A}}=p_{\mathrm{G}}$ in Eq. (9) and solving the system of Eqs. (8) and (9) with respect to $p_{\mathrm{G}}$ :

$p_{\mathrm{G}}=\frac{2 \mathrm{RT} \ln a_{\mathrm{W}}+\left(T-T_{0}\right) \Delta_{r, \mathrm{GA}} S^{0}-\Delta_{r, \mathrm{GA}} G^{0}-\frac{2 \gamma_{\mathrm{G}}}{r_{\mathrm{G}}} V_{\mathrm{G}}^{0}}{V_{\mathrm{G}}^{0}-V_{\mathrm{A}}^{0}}$

$\left(\right.$ for $\left.p_{\mathrm{A}}=p_{\mathrm{G}}\right)$,

where $\Delta_{r, \mathrm{GA}} S^{0}$ and $\Delta_{r, \mathrm{GA}} G^{0}$ are thermodynamic constants (see Notation and Table 1).

As mentioned above, Eq. (10) assumes that the anhydrite pressure is equal to the pressure developed by the gypsum crystals. If the latter are sparsely distributed within the rock matrix and located at greater distances from the anhydrite grains, the anhydrite will experience a smaller pressure increase than the walls of the pores constraining the gypsum growth. In the borderline case, where the anhydrite pressure remains equal to atmospheric pressure, the crystallisation pressure of gypsum can be determined by setting the ion concentrations in Eq. (8) equal to the equilibrium concentration of anhydrite under atmospheric pressure (i.e. from Eq. 9 with $p_{\mathrm{A}}=0$ ). We thus obtain the following equation:

$p_{\mathrm{G}}=\frac{2 R T \ln a_{\mathrm{W}}+\left(T-T_{0}\right) \Delta_{r, \mathrm{GA}} S^{0}-\Delta_{r, \mathrm{GA}} G^{0}-\frac{2 \gamma_{\mathrm{G}}}{r_{\mathrm{G}}} V_{\mathrm{G}}^{0}}{V_{\mathrm{G}}^{0}}$

$$
\text { (for } \left.p_{\mathrm{A}}=0\right) \text {. }
$$

Let us revisit now the question of "Relationship between crystallisation pressure and concentration" section, i.e. study the effect of temperature, water activity and pore size, taking into account the specific conditions prevailing in a closed system. Contrary to "Relationship between crystallisation pressure and concentration" section, we do not investigate here the effect of foreign ions $(\mathrm{NaCl})$, because the latter would increase both the gypsum and the anhydrite solubility with the consequence that the supersaturation and the crystallization pressure would not change (note that - contrary to Eq. (8) - the activity coefficients do not appear in Eqs. 10 and 11).

Figure $4 \mathrm{a}, \mathrm{b}$ and $\mathrm{c}$ show the crystallisation pressure as a function of temperature, water activity and pore size, 
respectively, for the two above-mentioned bounds of the anhydrite pressure (i.e. $p_{\mathrm{A}}=0$ or $p_{\mathrm{A}}=p_{\mathrm{G}}$ ). It is evident that in a system where anhydrite is the only ion supplier, the anhydrite pressure significantly influences the crystallisation pressure of gypsum.

As the equilibrium concentration of anhydrite depends on temperature, both the supersaturation with respect to gypsum and the crystallisation pressure of gypsum also depend on temperature (Fig. 4a). More specifically, with increasing temperature, the crystallisation pressure decreases by $1-2 \mathrm{MPa} /{ }^{\circ} \mathrm{C}$ depending on the anhydrite pressure.

According to Fig. 4c, the surface energy effect is relevant only for pore radii of up to $100 \mathrm{~nm}$. Figure $4 \mathrm{~d}$ gives an idea of the pore sizes of sulphatic claystones. More specifically, the diagram shows the results of mercury intrusion porosimetry (MIP) on samples from two Swiss tunnels crossing sulphatic claystones; the Chienberg Tunnel and the Belchen Tunnel. The diagram can be read in combination with the overlying diagram (Fig. 4c). Consider, for example, the curve for the sample from the Belchen tunnel and a percentage of $n=20 \%$. The corresponding pore radius and crystallisation pressure amount to about $12 \mathrm{~nm}$ (point A in Fig. 4d) and 8-21 MPa (points B and C in Fig. 4c), respectively. This means that in $80 \%$ of the total pore space (which consists of pores smaller than $12 \mathrm{~nm}$ ) the crystallisation pressure amounts to 8-21 MPa, which is significantly lower than the pressure in the remaining larger pores (20-52 MPa, Fig. 4c). The effect of the surface energy is thus significant in the case of the Belchen tunnel. By the same line of arguing, one can easily conclude from Fig. $4 \mathrm{c}$ and $\mathrm{d}$ that this effect is less important in the case of Chienberg Tunnel. The sample from this tunnel has considerably larger pores, probably due to the smaller depth of sampling (50 vs. $200 \mathrm{~m}$ ). Furthermore, the Chienberg Tunnel crosses the so-called Tafeljura, while the rock in the Belchen Tunnel belongs to the intensively folded part of the Jura mountains (the so-called Faltenjura), where high tectonic stresses may have caused additional compaction (Huggenberger 2014).

In conclusion, the thermodynamically possible range for the crystallisation pressure of gypsum is very wide even under the relatively simple conditions of a closed system. In the absence of surface energy effects or of interactions with clay minerals, the crystallisation pressure is equal to 20-50 MPa (Fig. $4 \mathrm{a}$ for $T=20^{\circ} \mathrm{C}$ ) depending on how much the pressure on the anhydrite particles increases due to the pressure exerted by the gypsum crystals upon the pore walls.

\section{Open systems}

In an open system, uncertainties exist with respect to the ion concentration. Consider, for example, the relatively
Fig. 4 Crystallisation pressure $p_{\mathrm{G}}$ of gypsum as a function (a) of the temperature $T$ (b) of the water activity $a_{\mathrm{W}}$ and (c) of the pore radius $r_{\mathrm{P}} ;(\mathbf{d})$ measured pore size distribution after Röthlisberger (2012) and Leemann and Wyrzykowski (2012)
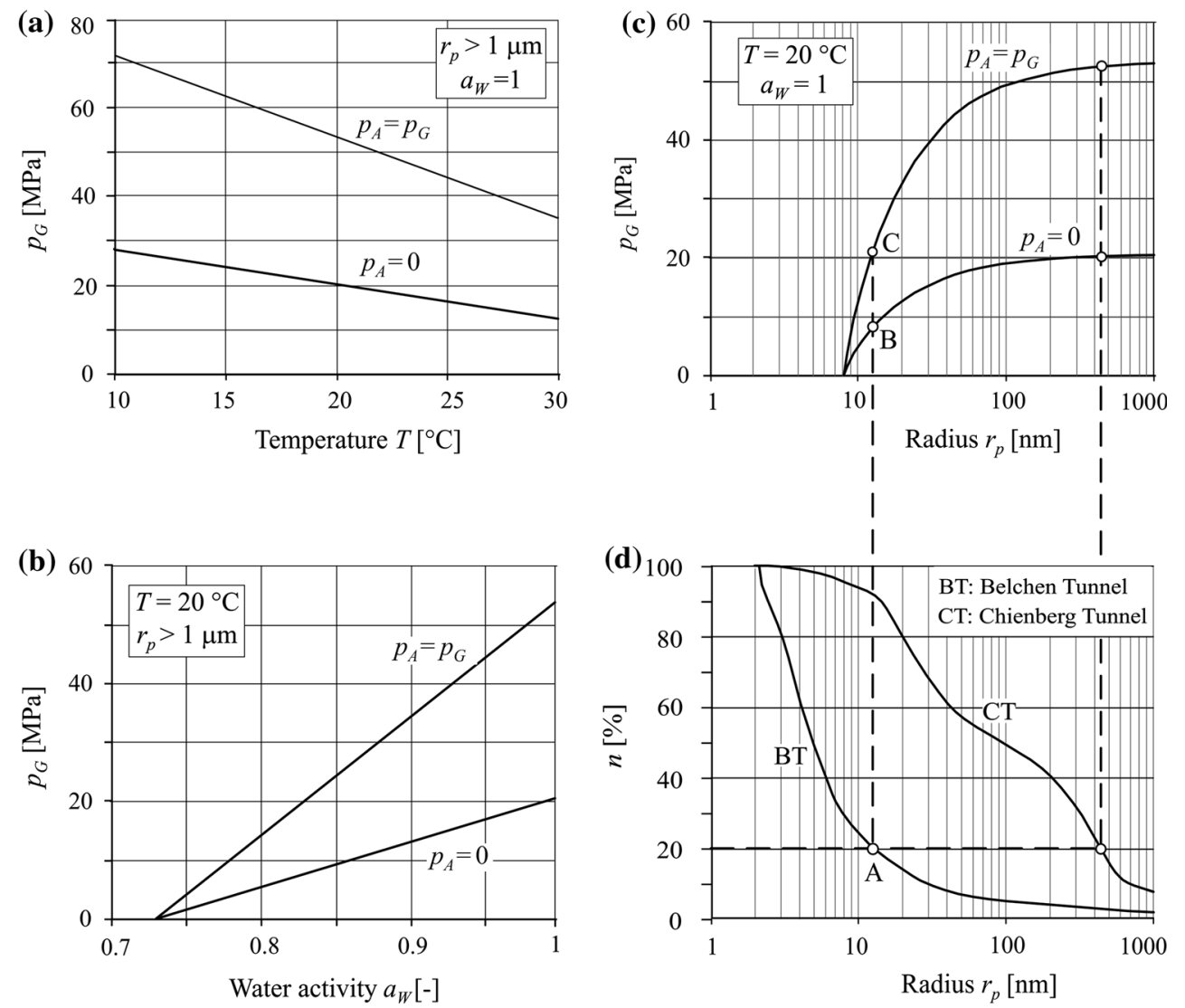

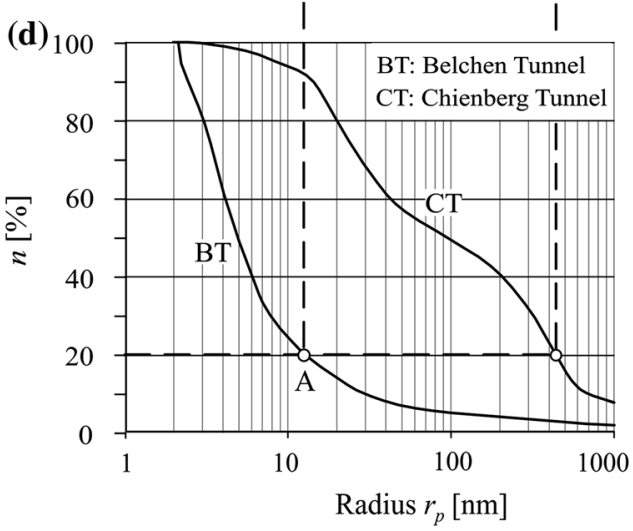


simple conditions of a rock sample placed in an oedometer device and immersed in a container of distilled water. Under the conditions of a swelling pressure test, the volume of the specimen is kept constant and consequently water uptake by and seepage flow towards the specimen is negligible. However, even in the absence of advection, it is possible that the ions produced by the dissolution of anhydrite move by diffusion out of the oedometer towards the water in the container. The ion concentration in the sample is governed by the combined effect of the anhydrite dissolution rate and the ion diffusion rate. If the diffusion rate is very high compared with that of the anhydrite dissolution, then the ion concentration in the pore solution and thus the crystallisation pressure of gypsum will be very low or even zero. On the other hand, if the diffusion is very slow, then the situation will be close to that of the closed system discussed above.

Generally, ion transport may also occur by advection. This is true particularly in situ due to the seepage flow around a tunnel. Seepage flow introduces an additional source of uncertainty, making a theoretical determination of the ion concentration and thus also of the crystallisation pressure in situ extremely difficult. The ion concentration in a rock element might vary from practically zero to values even higher than the equilibrium concentration of anhydrite. In the latter case, anhydrite should theoretically also start to precipitate or-if its crystal growth is constrained-exert a crystallisation pressure. However, according to Klepetsanis and Koutsoukos (1991), who investigated the precipitation of calcium sulphate within the temperature range $T=20-60{ }^{\circ} \mathrm{C}$, the only phase forming under these conditions is gypsum. The reason is that gypsum precipitates much more rapidly than anhydrite, thus consuming the ions of the pore solution before anhydrite grows. According to Fletcher and Merino (2001), who evaluated the experimental results of Liu and Nancollas (1970), the kinetic rate constant of anhydrite precipitation is lower than that of gypsum precipitation by a factor of about 200 .

In view of the practical difficulty of reliably estimating ion concentrations in situ, we will estimate crystallisation pressure on the basis of the concentrations measured in three Swiss tunnels crossing the Gypsum Keuper formation. Table 2 shows only the most important ions identified in the water chemical analyses, i.e. calcium- $\left(\mathrm{Ca}^{2+}\right)$, sulphate- $\left(\mathrm{SO}_{4}{ }^{2-}\right)$, sodium- $\left(\mathrm{Na}^{+}\right)$and chloride- $\left(\mathrm{Cl}^{-}\right)$ions.

As mentioned above, crystallisation pressure increases with the concentration of calcium and sulphate ions and decreases with the concentration of foreign ions (i.e. mainly sodium and chloride in the present case). Based upon the concentrations in Column 3-6 of Table 2 and assuming, for all three tunnels, that temperature $T=20^{\circ} \mathrm{C}$, water activity $\alpha_{\mathrm{W}}=1$ and that pore water pressure is atmospheric and the interfacial effects are

Table 2 Ion concentrations and crystallisation pressures derived from chemical analyses of the water in three Swiss tunnels crossing the Gypsum Keuper formation

\begin{tabular}{|c|c|c|c|c|c|c|}
\hline Tunnel (source) & Sample & $\begin{array}{l}\text { Sulphate } \\
\mathrm{SO}_{4}^{2-}[\mathrm{mg} / \mathrm{l}]\end{array}$ & $\begin{array}{l}\text { Calcium } \\
\mathrm{Ca}^{2+}[\mathrm{mg} / \mathrm{l}]\end{array}$ & $\begin{array}{l}\text { Sodium } \\
\mathrm{Na}^{+}[\mathrm{mg} / \mathrm{l}]\end{array}$ & $\begin{array}{l}\text { Chloride } \\
\mathrm{Cl}^{-}[\mathrm{mg} / \mathrm{l}]\end{array}$ & $p_{\mathrm{G}}[\mathrm{MPa}]$ \\
\hline \multirow[t]{3}{*}{$\begin{array}{l}\text { Belchen } \\
\text { (Noher and Meyer 2002) }\end{array}$} & $\begin{array}{l}\text { Collecting box } 1 \\
(19.6 .02)\end{array}$ & 2,174 & 566 & 638 & 336 & 3.27 \\
\hline & $\begin{array}{l}\text { Collecting box } 1 \\
(21.8 .02)\end{array}$ & 2,774 & 554 & 808 & 484 & 7.25 \\
\hline & $\begin{array}{l}\text { Collecting box } 3 \\
(24.7 .01)\end{array}$ & 2,565 & 752.9 & 2,628 & 2,319 & 6.16 \\
\hline Adler & Sample Nr. 9505819 & 1,864 & 602 & 42 & 196 & 4.73 \\
\hline (Bachema 1995) & Sample Nr. 95002582 & 1,686 & 577 & 64 & 103 & 1.61 \\
\hline \multirow[t]{6}{*}{$\begin{array}{l}\text { Chienberg } \\
\text { (LPM 2000-3) }\end{array}$} & $\begin{array}{l}\text { Field Nr. O1 } \\
(\mathrm{Tm} 1003)\end{array}$ & 2,000 & 620 & 16 & 20 & 7.83 \\
\hline & $\begin{array}{l}\text { Field Nr. O2 } \\
(\mathrm{Tm} 1059)\end{array}$ & 1,800 & 580 & 15 & 34 & 3.79 \\
\hline & $\begin{array}{l}\text { Field Nr. O10 } \\
(\text { Tm 1160) }\end{array}$ & 1,600 & 610 & 14 & 18 & 2.41 \\
\hline & $\begin{array}{l}\text { Field Nr. O12 } \\
(\text { Tm 1196) }\end{array}$ & 3,500 & 550 & 420 & 84 & 14.50 \\
\hline & $\begin{array}{l}\text { Field Nr. } 15 \\
(\text { Tm 862) }\end{array}$ & 1,750 & 860 & 200 & 41 & 10.80 \\
\hline & $\begin{array}{l}\text { Field Nr. } 16 \\
(\text { Tm 862) }\end{array}$ & 2,050 & 750 & 244 & 71 & 11.74 \\
\hline
\end{tabular}


negligible; Eq. (8) leads to gypsum crystallisation pressures of up to 7.25 MPa for the Belchen Tunnel, 14.5 MPa for the Chienberg tunnel and 4.73 MPa for the Adler Tunnel (last column of Table 2). These values are significantly lower than the crystallisation pressures in a closed system (20-50 MPa according to "Closing remarks" section).

\section{Closing remarks}

We have investigated the factors affecting the crystallisation pressure of gypsum by means of thermodynamic computations. We considered different scenarios with respect to supersaturation and obtained crystallisation pressures in the range of 20-50 MPa in the case of closed systems containing anhydrite, water and gypsum. Considerably lower pressures are obtained in the case of low water activities (which may be due to the electrostatic interactions of clay minerals), very small pores or when taking account of the ion concentrations measured in situ.

Concerning the practical engineering problem of swelling pressure in tunnelling, it should be noted that the macroscopically observed swelling pressure (i.e. the pressure that develops when the volume of a rock specimen containing gypsum crystals is kept constant) must be considerably lower than the crystallisation pressure. The reason is that the latter acts only locally within the rock matrix and, in addition, the matrix may act as a buffer which, depending on its stiffness, allows a certain amount of crystal growth to occur.

Acknowledgments The authors appreciate the support of the Swiss National Science Foundation (SNF, Project Nr. 200021-126717/1) and by the Swiss Federal Roads Office (FEDRO, Project Nr. FGU 2010-007).

\section{Appendix: on crystallisation pressure after Flückiger et al. (1994)}

From Eqs. (3)-(6), we obtain the following expression for crystallisation pressure according to Flückiger et al. (1994):

$p_{\mathrm{G}}=\frac{\Delta G_{r}(T)-\Delta G_{r}\left(T_{0}\right)}{V_{\mathrm{G}}^{0}}$.

The nominator of the right side is equal to the change in the Gibbs energy $\Delta G_{r}$ of the anhydrite hydration reaction due to a change in temperature from the standard temperature $T_{0}$ to another temperature $T$. It is well known (cf., e.g. White (2005) that

$\Delta G_{r}(T)-\Delta G_{r}\left(T_{0}\right)=-\left(T-T_{0}\right) \Delta_{r, \mathrm{GA}} S^{0}$,

where the standard entropy $\Delta_{r, \mathrm{GA}} S^{0}$ of the anhydrite hydration reaction can be determined from the molar entropies of the reaction products (gypsum) and reactants (anhydrite and water):

$\Delta_{r, \mathrm{GA}} S^{0}=S_{\mathrm{G}}^{0}-S_{\mathrm{A}}^{0}-2 S_{\mathrm{W}}^{0}$,

Taking into account the values of the molar constants according to Table 1, Eqs. (12)-(14) lead to

$p_{\mathrm{G}}=\frac{\left(T-T_{0}\right)\left(S_{\mathrm{G}}^{0}-S_{\mathrm{A}}^{0}-2 S_{\mathrm{W}}^{0}\right)}{V_{\mathrm{G}}^{0}} \cong 3.6 \mathrm{MPa}$.

This value is close to Flückiger et al. (1994) result (3.7 $\mathrm{MPa}$ ). The difference is due to rounding errors and to the fact that Flückiger (1994) used Kelley et al.'s (1941) empirical equation rather than the molar constants of Anderson (1996).

In the following, we will show that the pressure according to Eq. (15) is equal to the increase in the crystallisation pressure of the gypsum that would occur if the solution was permanently saturated with respect to anhydrite; the anhydrite was under atmospheric pressure and the temperature was reduced from the standard temperature of $T=T_{0}=25{ }^{\circ} \mathrm{C}$ (hereafter referred to as "state 1 ") to $T=20{ }^{\circ} \mathrm{C}$ (hereafter referred to as "state 2 "). The decrease in temperature causes an increase in the crystallisation pressure of the gypsum because the solubility of anhydrite increases with decreasing temperature (cf., Freyer and Voigt 2003, for example) and, consequently, supersaturation with respect to gypsum is higher in state 2 than in state 1 . At state 1 , the crystallisation pressure of gypsum reads as follows:

$p_{G 1}=\frac{R T}{V_{\mathrm{G}}^{0}} \ln \frac{K_{\mathrm{eq}, \mathrm{A}}^{0}}{K_{\mathrm{eq}, \mathrm{G}}^{0}}$,

where $K_{\text {eq,A }}^{0}$ and $K_{\text {eq,G }}^{0}$ denote the equilibrium solubility products of anhydrite and gypsum, respectively, at standard conditions. Eq. (16) follows directly from Eq. (2) considering that the solution is saturated with respect to anhydrite and, therefore, $K=K_{\mathrm{eq}, \mathrm{A}}^{0}$. The crystallisation pressure $p_{\mathrm{c} 2}$ at an arbitrary temperature $T$ can be calculated from the following equation (cf., e.g. White 2005):

$R T \ln \frac{K}{K_{\mathrm{eq}, \mathrm{G}}^{0}}=V_{G}^{0} p_{\mathrm{G} 2}+\left(T-T_{0}\right) \Delta_{r, \mathrm{G}} S^{0}$,

where the standard entropy of gypsum dissolution $\Delta_{r, \mathrm{G}} S^{0}$ can be determined from the molar entropies:

$\Delta_{r, \mathrm{G}} S^{0}=S_{\mathrm{Ca}^{2+}}^{0}+S_{\mathrm{SO}_{4}^{2-}}^{0}+2 S_{\mathrm{W}}^{0}-S_{\mathrm{G}}^{0}$

If the solution is always saturated with respect to anhydrite and the anhydrite is under atmospheric pressure, then the solubility product $K$ can be obtained (analogously to Eq. 17) from the following equation:

$R T \ln \frac{K}{K_{\text {eq,A }}^{0}}=\left(T-T_{0}\right) \Delta_{r, \mathrm{~A}} S^{0}$,

where the standard entropy of anhydrite dissolution is 
$\Delta_{r, \mathrm{~A}} S^{0}=S_{\mathrm{Ca}^{2+}}^{0}+S_{\mathrm{SO}_{4}^{2-}}^{0}-S_{\mathrm{A}}^{0}$

Inserting $K$ from Eq. (19) into Eq. (17) and taking account of Eqs. (14) (18) and (20) leads to the following expression for the crystallisation pressure of gypsum in state 2:

$p_{G 2}=p_{G 1}+\left(T-T_{0}\right) \frac{S_{G}^{0}-S_{A}^{0}-2 S_{W}^{0}}{V_{G}^{0}}$.

The last term on the right side of this equation is identical with Eq. (15). This means that the value determined by Flückiger et al. (1994) is equal to the change in the crystallisation pressure $\left(p_{\mathrm{G} 2}-p_{\mathrm{G} 1}\right)$ that would occur if the temperature decreases from $T_{O}=25{ }^{\circ} \mathrm{C}$ to $T=20{ }^{\circ} \mathrm{C}$.

\section{References}

Amstad C, Kovári K (2001) Untertagbau in quellfähigem Fels. Schlussbericht Forschungsauftrag 52/94 des Bundesamts für Strassen ASTRA

Anderson GM (1996) Thermodynamics of natural systems. University of Toronto. Wiley, New York

Bachema (1995) Chemische Untersuchung von Wasserproben Adlertunnel Bahn 2000. Several reports by "Institut Bachema AG, Analytische Laboratorien"

Blount CW, Dickson FW (1973) Gypsum-anhydrite equilibria in systems $\mathrm{CaSO}_{4}-\mathrm{H}_{2} \mathrm{O}$ and $\mathrm{CaCO}_{3}-\mathrm{NaCl}-\mathrm{H}_{2} \mathrm{O}$. Am Mineral 58:323-331

Correns CW, Steinborn W (1939) Experimente zur Messung und Erklärung der sogenannten Kristallisationskraft. Z Krist (A) $101: 117-133$

Davies CW (1962) Ion association. Butterwoths, London

Flatt RJ (2002) Salt damage in porous materials: how high supersaturations are generated. J Cryst Growth 242:435-454

Flatt RJ, Steiger M, Scherer GW (2007) A commented translation of the paper by C.W. Correns and W. Steinborn on crystallization pressure. Environ Geol 52:187-203

Fletcher RC, Merino E (2001) Mineral growth in rocks: kineticrheological models of replacement, vein formation, and syntectonic crystallization. Geochim Cosmochim Acta 65(21):37333748

Flückiger A (1994) Anhydritquellung. Rencontre Internationale des jeunes chercheurs en geologie appliquees, Lausanne, 21 Avril 1994, 103-107

Flückiger A, Nüesch R, Madsen F (1994) Anhydritquellung. Berichte zur Jahrestagung Regensburg der Deutschen Ton und Tonmineralgruppe e.V., 146-153

Freyer D, Voigt W (2003) Crystallization and phase stability of CaSO4 of and CaSO4-based salts. Monatsh Chem 134:693-719

Gmelin L (1961) Gmelins Handbuch der anorganischen Chemie Calcium. Gmelin-Institut, Max-Planck-Gesellschaft

Huggenberger P (2014) University of Basle, Personal communication
Kelley KK, Southard JC, Anderson CT (1941) Thermodynamic properties of gypsum and its dehydration products. U.S G.P.O., Bureau of Mines, Washington, p 73

Klepetsanis GP, Koutsoukos GP (1991) Spontaneous precipitation of calcium sulfate at conditions of sustained supersaturation. J Colloid Interface Sci 143(2):299-308

Leemann A, Wyrzykowski M (2012) MIP tests on gypsum Keuper samples from the Chienberg and Belchen Tunnel. Internal laboratory test report, EMPA

Liu S-T, Nancollas HG (1970) The kinetics of crystal growth of calcium sulfate dihydrate. J Cryst Growth 6:281-289

LPM (2000-3) Wasseranalysen Chienberg Tunnel. Several reports by "Labor für Prüfung und Materialtechnologie"

Marsal D (1952) Der Einfluss des Druckes auf das System CaSO4H2O. Heidelberger Beiträge zur Mineralogie and Petrographie 3:289-296

Merino E, Dewers Th (1998) Implications of replacement for reaction-transport modeling. J Hydrol 209:137-146

Merkel JB, Planer-Friedrich B (2008) Groundwater geochemistry, 2nd edition. Springer, Berlin

Noher H-P, Meyer N (2002) Belchentunnel Versuchsdrainagestollen, Beurteilung der Wasseranalysen. Report 1510720.003 by Geotechnisches Institut AG

Pimentel E (2007) Quellverhalten von Gesteinen - Erkenntisse aus Laboruntersuchungen. Quellprobleme in der Geotechnik, Mitteilungen der Schweizerischen Gesellschaft für Boden- und Felsmechanik, Frühjahrstagung Freiburg, No. 154:11-20

Ping X, Beaudoin J (1992) Mechanism of sulphate expansion: I. Thermodynamic principle of crystallization pressure. Cem Concr Res 22:631-640

Röthlisberger A (2012) MIP tests on gypsum Keuper samples from the Chienberg and Belchen Tunnel. Internal laboratory test report, Institute for Geotechnical Engineering, ETH Zurich

Scherer GW (1999) Crystallization in pores. Cem Concr Res 29:1347-1358

Serafeimidis K, Anagnostou G (2012) On the kinetics of the chemical reactions underlying the swelling of an hydritic rocks. Eurock 2012, Stockholm

Serafeimidis K, Anagnostou G (2014) The solubilities and thermodynamic equilibrium of anhydrite and gypsum. Rock Mech Rock Eng. doi:10.1007/s00603-014-0557-1

Steiger M (2005) Crystal growth in porous materials-II: influence of crystal size on the crystallization pressure. J Cryst Growth 282:470-481

Steiner W, Kaiser KP, Spaun G (2010) Role of brittle fracture on swelling behaviour of weak rock tunnels: hypothesis and qualitative evidence. Geomech Tunnel 3:583-596

Washburn EW (1926-1933) International critical tables of numerical data, physics, chemistry and technology. New York, Published for the National Research Council by McGraw-Hill

White WM (2005) Geochemistry. John-Hopkins University Press, Baltimore

Wichter L (1989) Quellen anhydrithaltiger Tongesteine. Bautechnik 66, Heft 1

Winkler EM (1973) Stone: properties durability in man's environment. Springer, Berlin

Winkler EM, Singer PC (1972) Crystallization pressure of salts in stone and concrete. Geol Soc Am Bull 83:3509-3514 